\title{
A história da primeira tentativa de produção de medicamentos à base de maconha: Entrevista com Antônio José Alves
}

\author{
The history of the first attempt to produce marijuana-based \\ medicines: Interview with Antônio José Alves
}

Antonio Gomes de Castro Neto (https://orcid.org/0000-0003-0174-715X) ${ }^{1}$

José Arturo Costa Escobar (https://orcid.org/0000-0002-5965-3327) ${ }^{2}$

Wagner Lins Lira (https://orcid.org/0000-0002-5174-980X) ${ }^{3}$

${ }^{1}$ Departamento de Fisiologia e Farmacologia, Universidade Federal de Pernambuco. Av. da Engenharia s/n, Cidade Universitária. 50670-420 Recife PE Brasil.

litaree@yahoo.com ${ }^{2}$ Grupo de Estudos sobre Álcool e outras Drogas, Universidade Federal de Pernambuco. Recife PE Brasil.

${ }^{3}$ Departamento de Educação, Universidade Federal Rural de Pernambuco. Recife PE Brasil.

\begin{abstract}
The debate over marijuana regulation has gained strength in recent years, due to its therapeutic potential. Despite this, there is still a lot of prejudice related to the use of medical marijuana. In the mid-1990s, Lafepe proposed to produce a Cannabis sativa-based medicine. This proposal was pioneering at a time when the discussion about drugs was still surrounded by intense prohibitions and prejudice. This work aims to rescue, through an interview with Professor Antônio José Alves, President of Lafepe at the time, all the paths and obstacles taken in the avant-garde attempt to create the first marijuana-based medicine made in Brazil.
\end{abstract}

Key words Cannabis, Medical marijuana, Pharmaceutical formulations, National Health Surveillance Agency
Resumo O debate acerca da regulamentação da maconha ganhou força nos últimos anos, devido seu potencial terapêutico. Apesar disso ainda existe muito preconceito em relação à utilização da maconha medicinal. Em meados dos anos 1990, o Lafepe trouxe a proposta da produção de um medicamento à base de Cannabis sativa. Essa proposta foi pioneira numa época na qual a discussão sobre as drogas ainda era cercada de intenso proibicionismo e preconceitos. Este trabalho visa resgatar por meio de uma entrevista com o Professor Antônio José Alves, Presidente do Lafepe da época, todos os caminhos entraves percorridos na tentativa de vanguarda da criação do primeiro medicamento feito com maconha no Brasil.

Palavras-chave Cannabis, Maconha medicinal, Preparações farmacêuticas, Agência Nacional de Vigilância Sanitária 


\section{Introdução}

$\mathrm{Na}$ atualidade, vivenciamos um momento particular global de redescoberta das propriedades terapêuticas da Cannabis, assim como o reconhecimento de alguns países a respeito do direito à autonomia do uso medicinal e recreativo da planta. O Brasil, por sua vez, experimenta uma variedade significativa de reivindicações advindas, especialmente, de alguns movimentos sociais, políticos e científicos. Esses movimentos sinalizam para a vigente necessidade da regulação da maconha para fins medicinais, sobretudo motivados pelos elevados custos de importação, burocracia e urgência para o tratamento de patologias pela administração de canabinóides (epilepsia, escleroses, anorexia, dor neuropática, fibromialgias, etc.).

Durante o segundo governo de Miguel Arraes de Alencar (1995 a 1998) o estado de Pernambuco vivenciou a criação de programas e projetos que buscavam alcançar parcelas mais carentes da população. Dentre esses vários projetos realizados houve o fortalecimento de empresas e indústrias estatais, como o Laboratório Farmacêutico do Estado de Pernambuco (Lafepe) o qual apresentou significativa relevância nos âmbitos da produção de medicamentos a preços populares e da pesquisa farmacêutica. O Lafepe destacou-se na produção de medicamentos antirretrovirais e foi a primeira instituição do país a elaborar um pedido formal para produção de um medicamento derivado de maconha; 20 anos antes da aprovação do primeiro fármaco autorizado pela Agência Nacional de Vigilância Sanitária (Anvisa).

Este pedido foi realizado pelo então presidente do Lafepe o Dr. Antônio José Alves - atualmente Professor Titular do Departamento de Ciências Farmacêuticas da Universidade Federal de Pernambuco (UFPE). O Prof. Antônio Alves é pernambucano, nascido em uma família de baixa renda, mas devido a sua dedicação com os estudos, formou-se em Farmácia pela UFPE e realizou o doutorado em Montpelier, França. Realizou ainda o pós-doutorado nos Estados Unidos, tendo trabalhado com medicamentos para o combate ao HIV, o que lhe rendeu uma proposta, ao retornar para o Brasil, em assumir a diretoria do Lafepe. Nesse período como diretor da instituição, realizou diversos projetos de produção de medicamentos a preços populares, sobretudo para o tratamento da Aids. Por conta de uma reportagem na televisão, teve a ideia de produzir um medicamento a base de Cannabis para o tratamento de pacientes com Aids, câncer e epilepsia.

Sendo assim, pretendemos por meio desta breve entrevista, buscar elucidar os (des) caminhos percorridos acerca desse registro histórico. Além disso, fomentar o debate para o potencial nacional, e em particular do Estado de Pernambuco - por meio da expertise do Lafepe na produção de medicamentos de qualidade e de baixo custo - para a possível e necessária produção de medicamentos à base de Cannabis.

\section{Entrevista}

Gead: Dr. Antônio Alves, sobre sua formação, o senhor poderia falar como foi, à época, suas escolhas nesse percurso profissional?

Antônio Alves: Meu pai era ex-cortador de cana da zona da mata de Pernambuco e minha mãe lavadeira do município de São Caetano, que fica depois de Caruaru. Tive doze irmãos, cinco morreram até quatro anos de idade; mortalidade infantil! Meu pai sempre queria que eu estudasse, então comecei a estudar sozinho. Tudo isso de militares, de movimento estudantil de luta contra ditadura, eu não vivi. Meu irmão que falava sobre isso, mas eu não percebia. Eu me escondi do mundo pra estudar e eu não tomava conhecimento dos fatos que ocorriam. Nisso eu fiz (vestibular) e passei aqui (na UFPE) para farmácia. Quando terminei a faculdade apareceu uma proposta de mestrado na área de química e resolvi fazer. Eu não sabia química. Comecei o mestrado, às vezes minhas notas eram baixas, mas como eu estudava muito conseguia passar. Apesar disso eu não tinha conhecimento do mundo, eu nem sabia o que era isso, maconha; de vez em quando mamãe falava: "olhe não se junte com esses maconheiros não". Eu sabia que existia a droga, mas não o que era! Terminei o mestrado e fui pra Paraíba. Fui professor da Universidade Federal da Paraíba (UFPB) e então uma professora daqui da UFPE me convidou porque estavam fazendo uma parceria com a França. Pedi demissão da UFPB e fiquei aqui como visitante na UFPE. Então fui enviado para França sem dinheiro, sem visto, sem falar francês... Cheguei à Paris, deram-me o telefone de uma pessoa que atendeu me buscou e me levou para a casa dele e disse: "vou lhe mandar pra Montpellier". Cheguei à Montpellier, as pessoas se reuniram lá e disseram: "você tem um mês para se organizar senão depois pode ser deportado". Sem saber francês, perder o curso, perder tudo! Eu tive que aprender rápido e fiz o 
doutorado de Estado. Eu estudava muito e não vi a França passar na minha cabeça. Então eu cheguei ao doutorado sem conhecer o mundo. Ainda assim fiz pós-doutorado nos Estados Unidos trabalhando com medicamentos para combater o HIV. Quando retornei ao Brasil tive um convite do Governador Arraes! Eu não tinha como negar e fui para o Laboratório Farmacêutico de Pernambuco (Lafepe) onde comecei a fazer alguns projetos. Percebi na época que era uma grande batalha dos portadores de HIV por medicamento e assistência. Estive à frente do Lafepe de 1994 até 1998. Propus para Arraes: "vamos produzir medicamentos de Aids no Lafepe”. Ele disse: "não, eu quero produzir medicamento para o povo". Eu disse: "nós não temos dinheiro. Se produzir medicamento de Aids, vamos ter dinheiro e depois faço os medicamentos para o povo". Foi então que ele concordou. Fomos pioneiros no mundo em lançar genéricos. Os genéricos já existiam, obviamente, só que ninguém ousava expor-se porque se fizessem as multinacionais cortavam! Quando começamos a produzir na época tinha um medicamento que custava um dólar o comprimido, eu reduzia para cinquenta centavos! O faturamento do Lafepe que até então era de cinco milhões de dólares por ano, depois que assumi teve mês que faturei dez milhões de dólares. Depois de um fôlego comecei a enfrentar uma guerra grande para conseguir verba dos Ministérios.

Gead: O senhor ficou por quanto tempo no Lafepe?

Antônio Alves: Foram quatro anos.

Gead: Como se aproximou com a questão do uso medicinal da Cannabis?

Antônio Alves: Comecei a fazer inúmeros projetos: Centros Sociais Urbanos (CSU), farmácias populares, irrigação de cana-de-açúcar. Doutor Arraes achava que ia perder (a eleição) então começava a me colocar nos projetos dele... Enfim, eu comecei a ajudar e na época eu vi que a Polícia Federal pegava a Cannabis sativa, apreendia e tocava fogo! Como eu estava envolvido em inúmeros projetos eu disse: "vou fazer um projeto..."

Gead: Como surgiu a ideia de produzir o medicamento à base de Cannabis no Lafepe?

Antônio Alves: No início Arraes me chamou pra coordenar a Central de Medicamentos. Eu simplesmente achei que eu deveria fazer. Eu não podia achar natural queimar toneladas de erva, tendo utilidade...

Gead: Foi nessa época que Pernambuco estava entre os maiores produtores de maconha do mundo?

Antônio Alves: Justamente! Então eu disse: "por que não?” Em vez de queimar, trazer para o Lafepe, extrair a matéria prima e colocava para fazer pesquisa também. Na época eu falei que era para paciente de Aids e para paciente de câncer. Também poderia exportar, porque na época Israel e os Estados Unidos já usavam a matéria prima da Cannabis. Só pra citar um fato... Eu lembro como se fosse hoje; eram sete horas da manhã anunciaram no jornal da televisão: "o Lafepe solicitou autorização no Conselho Federal de Entorpecentes (CONFEN) e foi negado"; foi uma confusão, meu telefone tocava direto e eu ainda não tinha falado para Arraes! À tarde eu fui lá (no Palácio do Governo) teve essa confusão, mas o projeto foi negado. Eu ainda briguei com o povo lá... E eu ainda tenho aqui os documentos. Este aqui de 29 de novembro de 1996: “(...) com relação ao expediente de utilização da Cannabis sativa" com a assinatura do responsável do CONFEN na época. O projeto visava atender pacientes de Aids e câncer e eu mencionava também de tudo o que está se usando hoje para tratar epilepsia... "toda a manipulação feita no âmbito deste laboratório deverá ser feita com a quantidade aproximada de cento e cinquenta quilos de vegetal, cujo princípio ativo depois extraído será transformado em cápsulas". Esse processo foi mandado para a Secretaria de Vigilância Sanitária (SVS) para ter autorização. Na realidade eu não estava querendo legalizar nada! Só estava querendo passar pelos trâmites legais para oficializar o processo todo.

Gead: Como era sua percepção sobre a questão das drogas nessa época na academia e como era tratada na sociedade? $O$ senhor pode falar também de sua visão pessoal sobre o tema à época e como o senhor vê hoje (sobre o uso/abuso de drogas, dependência, regulação/legalização, políticas públicas, etc.)?

Antônio Alves: Eu só comecei (com o Processo da Cannabis) porque achei que era desperdício, aquilo não podia ser assim... Nunca fumei, nem experimentei cigarro! Não tenho vício nenhum, mas, mesmo assim, me lancei para fazer esse projeto só por conta do desperdício. Só por isso! Eu não entendia nada sobre regulação, descrimina- 
lização e legalização de drogas. Comecei a entender posteriormente devido a farmacologia, a parte de psicofarmacologia, que eu estudei muito, mas não sabia o que era mercado, o que era consumo (de drogas)... Então, eu comecei a fazer algum juízo de valor; hoje eu leio sobre política e emito algumas considerações. Com relação às drogas, eu sou particularmente contra, até pela minha história.

Gead: Então o Senhor é contra a regulação, descriminalização e legalização da maconha?

Antônio Alves: Sim.

\section{Gead: Mesmo medicinal?}

Antônio Alves: Se for medicinal, que só pode comprar com prescrição médica eu sou a favor. Que no caso aqui (do Processo da Cannabis) era um medicamento, não era uma droga recreativa! Por acaso está sendo extraído esse princípio ativo de uma erva que é considerada droga. Mas como medicamento, eu sou a favor e foi por isso que eu me lancei nessa seara, mas eu sou contra legalizar para ser droga recreativa.

Gead: Na época Professor, o Senhor propôs a ideia de trazer a matéria prima pelo Lafepe para poder fazer pesquisa ou era já para fazer medicamento?

Antônio Alves: Já existia um medicamento, o Dronabinol, e a pesquisa. Eu ia produzir o medicamento e fazer pesquisa também, claro. E o tetrahidrocanabinol (THC) na época não tinha registro, mas mesmo que ele tivesse ninguém poderia patentear porque é um produto natural extraído de planta. Ele não se pode patentear; eu não posso usar o nome Dronabinol, mas o THC e os outros componentes eu podia lançar. Não tem patente de produto natural que não foi feito. A pessoa não inventou a molécula, ela já existe. Agora o nome Dronabinol eu não podia usar. Eu iria usar THC ou iria usar outro nome...

Gead: Mas o Senhor lembra o direcionamento? Esse medicamento era direcionado para qual patologia? Para qual doença?

Antônio Alves: Era para pacientes de Aids, que tinham vômitos e ânsias de vômitos que é insuportável e ele era um excelente antiemético. Para pacientes de câncer e para pacientes de epilepsia. E já se usava naquela época! Os Estados Unidos usavam e em Israel também e uma das ideias do projeto era exportar a matéria prima para um desses países.

Gead: Mas a apresentação, o Senhor ia fazer como fitoterápico ou purificado?

Antônio Alves: Purificado! Era o THC e os outros canabinóides, porque na época o THC era importante, mas pra fazer a medicação podia usar os outros canabinóides... Eu mudei o nome do medicamento, seria Dranabinol; para mudar o nome registrado Dronabinol deles. As mesmas técnicas de produção dos medicamentos de Aids que eu fazia seriam utilizadas para produzir o medicamento a base de Cannabis. Eu chamava os infectologistas do Brasil pra ver; fazia apresentação, nós publicamos muito sobre isso. Eu fazia igual no medicamento de Aids!

Gead: O senhor lembra os estudos utilizados na época para embasar a iniciativa, qual era o direcionamento terapêutico do medicamento?

Antônio Alves: Já tinham estudos de Carlini na área e usei esses estudos para fundamentar o projeto. Tem tudo documentado eu fiz um trabalho que não era para ser engavetado. Eu cheguei até a publicar um artigo de revisão sobre isso. Mas eu fiquei com raiva do CONFEN e da SVS e eu contestei! Eu contestei e eles ficaram com raiva ainda, mas depois deve ter passado.

Gead: Na Secretaria de Vigilância Sanitária havia defensores de uma agência de Cannabis medicinal; o Senhor podia explicar um pouco essa posição da negativa por parte da agência?

Antônio Alves: Eles me disseram os procedimentos e eu fui fazendo. Fiz o protocolo para a SVS, era para solicitar autorização do Conselho Federal de Entorpecentes... Eu fiz isso, entrei pra resolver a questão, mas só negaram. Deram uma justificativa e ainda contestei, mas depois deixei por isso mesmo.

Gead: Seu projeto foi a tentativa mais clara e próxima de ter chegado à produção do medicamento. Partindo da indústria, quando normalmente essas ideias deveriam partir das universidades.

Antônio Alves: Esse pedido aqui saiu de uma indústria de medicamentos. Até porque eu não suporto burocracia demais. Se você quer fazer 
Conforme as cópias dos documentos da época, gentilmente cedidos pelo Prof. Antônio José Alves, o secretário da Anvisa era o Prof. Elisaldo Carlini, um dos pioneiros na pesquisa e defensor do uso medicinal da Cannabis. A negativa narrada pelo Prof. Antônio José Alves, tendo a assinatura do Prof. Elisaldo Carlini nos chamou a atenção. Nós o contatamos e cordialmente ele comentou o fato.

Elisaldo Carlini: Recebi um convite que muito me honrou: o de descrever rapidamente, o encontro que tive com o Antônio José Alves, diretor do Lafepe. Ele vinha com aval do Arraes e eu fui chefe de Vigilância Sanitária do Ministério da Saúde do Ministro Adib Jatene. Era simplesmente algo incomum: dois professores universitários - Alves e Carlini, tendo a indicação e apoio de dois grandes brasileiros - Arraes e Jatene. E assim ocorreu uma primeira reunião Alves/Carlini, no Ministério da Saúde em Brasília. O ano foi 1996. Mostrei a ele que seria muito difícil, pois a lista de documentos, autorizações, fiscalizações era enorme e não deve (como até hoje) resolver nada a não ser muito lentamente. Tive uma segunda reunião depois e afirmei que a autorização para fabricação deveria antecipadamente ser aprovada. A situação ficou muito complicada para o colega Alves, quando o CONFEN da época negou o pleito dele. Apesar da insistência junto à SVS, nós nesta Secretaria não podíamos mesmo aprovar o uso de canabinóides em clinica como era pretendido: "O projeto visava pacientes de Aids, câncer e epilepsia", sem receber um parecer favorável das Comissões de Éticas das autoridades competentes. Na realidade, o que se pretendia fazer no Lafepe seria isolar os canabinóides (inclusive o THC), mencionando o dronabinol; e este composto é o que se considerou chamar de dranabinol. Os esforços de Alves não tiveram prosseguimento e, portanto, não foi um sucesso. E não se tem nenhuma notícia de isolamento do THC ou CBD puros. Mas já existem várias tentativas em andamento nas quais se consegue preparar extratos de maconha enriquecidos com o canabidiol, o canabinoide preferido em clínica hoje em dia. Considero o Antônio José Alves um dos exemplos da ciência brasileira. Numa época ingrata tentou o "sonho impossível". Não importa que não tenha conseguido impedido pela paralisante burocracia brasileira. Houvesse uma política menos conservadora e que realmente apoiasse nossa gente cientifica, o desfecho bem poderia ser outro. Mas até hoje me orgulho e tenho a honra de ter discutir com ele este projeto.

\section{Colaboradores}

AG Castro Neto: elaboração das perguntas, realização da entrevista, edição e revisão final do manuscrito. JAC Escobar: elaboração das perguntas, realização da entrevista, revisão final do manuscrito. WL Lira: elaboração das perguntas, transcrição da entrevista, revisão final do manuscrito. 


\section{Agradecimentos}

Agradecemos ao Professor Doutor Antônio José Alves e ao Professor Doutor Elisaldo Carlini pela disponibilidade para as entrevistas, por ter nos cedido importantes materiais para a composição deste trabalho e por autorizar a reprodução do mesmo.

Artigo submetido em 09/08/2018

Aprovado em 28/09/2018

Versão final apresentada em 30/09/2018 